\title{
Inovação e Território Local: um estudo sobre capacitação tecnológica em cidades selecionadas ${ }^{*}$
}

\author{
Humberto E.P. Martins
}

Professor do Instituto de Economia da Universidade Federal de Uberlândia - UFU

\section{RESUMO}

Este trabalho desenvolve uma investigação sobre capacitação tecnológica em um grupo de empresas localizadas em três cidades selecionadas na Região Sudeste brasileira, a saber: Uberlândia e Pouso Alegre, em Minas Gerais, e Resende, no Estado do Rio de Janeiro. Depois da introdução, na segunda seção são discutidas novas abordagens e concepçôes acerca da inovação tecnológica, que consideram a importância das interaçōes e do território local para a inovação. Na terceira seção apresentam-se a estrutura do estudo empírico e a caracterização das cidades selecionadas. Por fim, na quarta seção, são apresentados e discutidos os resultados do estudo empírico, que se referem à capacidade inovativa, às fontes de conhecimento das empresas e às práticas de terceirização do processo produtivo.

Palavras-Chave | Inovação; Capacitação Tecnológica; Território Local; Cidades Códigos JEL $\quad$ O31; O32; O33

\footnotetext{
* O autor agradece aos dois pareceristas anônimos pelos comentários e sugestões pertinentes.
} 


\section{ABSTRACT}

This article analyses the technological capability in some companies located in three cities within the Southeast region of Brazil: Uberlândia, Pouso Alegre (both in the State of Minas Gerais) and Resende (State of Rio de Janeiro). After an introduction, the second section discusses new approaches and conceptions about technological innovation, which highlights the importance of interactions and local space for the innovation process. The third section presents the framework of the empirical study and characterizes the selected cities. The fourth section shows and analyses the empirical findings, which are related to innovation capacity, knowledge sources and outsourcing practices.

KEYWORDS | Innovation Process; Technological Capability; Local Territory; Cities JEL-CODES I O31; O32; O33

\section{Introdução}

Os estudos referentes à inovação tecnológica têm, crescentemente, incorporado elementos ligados ao ambiente em que a empresa se insere, considerado em sentido amplo. Essa incorporação vai muito além da consideração das "externalidades", tomadas de uma maneira genérica e abstrata, como é feito nas abordagens tradicionais. Parte desses elementos pode ser captada pela noção de "economias de escopo", mas parte significativa envolve práticas de cooperação e mecanismos de difusão que extrapolam também essa noção.

Assim, "entorno favorável”, "meio inovador" e "ambiente local" são exemplos de noções desenvolvidas com a perspectiva de incorporar essa dimensão 
relacional da empresa com o meio externo em que ela está inserida, que influencia seu processo de inovação e de capacitação tecnológica. Nesse contexto, diversos indicadores têm sido desenvolvidos com o objetivo de captar, identificar e mensurar as interações que a empresa realiza com outros agentes nesse espaço que extrapola os limites das firmas individuais. Particularmente, a importância do território local e das instituições locais tem sido ressaltada na bibliografia sobre o tema. A elaboração de estudos com essa perspectiva certamente contribui para melhor compreensão do processo de inovação.

Este trabalho apresenta uma pesquisa de campo que examina esse tema em três cidades que cumprem papel relevante na rede urbana brasileira, em especial no Sudeste, a saber: Uberlândia (MG), Pouso Alegre (MG) e Resende $(\mathrm{RJ})$. As principais questóes focalizadas referem-se à capacidade tecnológica das empresas, às fontes de conhecimento por elas utilizadas e às práticas de terceirização implementadas. Busca-se, em especial, dimensionar a importância do território local para a capacitação tecnológica das empresas. A pesquisa foi realizada por meio de entrevistas em empresas selecionadas nos principais segmentos industriais de cada cidade.

O trabalho é estruturado da seguinte maneira. Primeiramente, discutem-se novas abordagens acerca da inovação e a recente incorporação do território local nessas novas concepções, conforme bibliografia referente ao tema. Em seguida, apresenta-se a estrutura do estudo empírico, bem como se caracteriza a estrutura produtiva e industrial das cidades selecionadas. Posteriormente, são apresentados e discutidos os resultados do estudo empírico, que se referem à capacidade inovativa, às fontes de conhecimento e às práticas de terceirização presentes no processo produtivo. As consideraçôes finais ressaltam a importância do território local para a capacitação tecnológica do conjunto de empresas, discutindo as especificidades demonstradas pelas empresas de cada cidade.

\section{A dimensão local da inovação tecnológica}

Durante muito tempo, a inovação tecnológica foi vista como um "subproduto" da atividade produtiva e tratada como um bem que podia ser adquirido livremente no mercado. Na concepção neoclássica, a tecnologia é considerada dada 
e livremente acessível, possuindo um caráter exógeno, no contexto da alocação ótima de recursos. Assim, o princípio organizador do sistema é a racionalidade econômica dos agentes individuais, tomada como procedimento invariável de maximização de algumas funções objetivas conhecidas (Dosi \& Orsenigo, 1988:14).

Nas últimas décadas, o desenvolvimento de abordagens alternativas às ortodoxas favoreceu a concepção da inovação tecnológica como um processo interativo, em que estão presentes diversos agentes, reforçando a importância do meio em que a empresa está inserida. Nesse contexto, duas abordagens podem ser destacadas: a abordagem neo-schumpeteriana e a abordagem do meio inovador.

A abordagem neo-schumpeteriana, diferentemente da visão atomizada da economia presente nas abordagens ortodoxas, enfatiza a interdependência sistêmica que existe entre sujeitos econômicos formalmente independentes (Lundvall, 1988:350). Essa visão é sintetizada no conceito de "Aprendizado por Interação" (Learning by Interacting), em que a inovação assume a forma de um processo interativo, baseando-se em um contínuo intercâmbio de informações e procedimentos de cooperação direta (Lundvall, 1988:352353). O conceito de "Aprendizado por Interação" fundamentou duas importantes concepções presentes na abordagem neo-schumpeteriana: os sistemas de inovação e as redes de firmas.

A concepção de sistemas de inovação enfatiza a interação entre diversos elementos participantes do processo de inovação, que é percebido como um processo cumulativo, de permanente retroalimentação, tendo em seu centro a empresa. Essa concepção foi desenvolvida pelos teóricos neoschumpeterianos no final da década de 1980, notadamente Lundvall (1988), que enfatizou a relação produtor-usuário e Freeman (1988), cuja análise demonstrou a grande importância das inovações sociais e institucionais na perspectivas dos sistemas de inovação.

A concepção de redes de firmas focaliza a configuração, a natureza e o conteúdo de uma série de relações interorganizacionais. A abordagem neoschumpeteriana procura resgatar os aspectos dinâmicos das redes de firmas, como a criação de conhecimento por meio da interação, a acumulação dinâmica de tecnologia e o caráter social do aprendizado (DeBresson \& Amasse, 1991:364). 
A idéia de que a inovação raramente é realizada por uma empresa isoladamente constitui o fundamento da abordagem das redes de firmas desenvolvida por DeBresson (1999). Sobre as redes de firmas, Britto (1999:113) assinala que abordagem neo-schumpeteriana enfatiza a "eficiência dinâmica, associada ao reforço do potencial inovativo proporcionado pela integração de múltiplas competências no interior daqueles arranjos".

Assim, a inovação é vista como um processo interativo. Além desse aspecto, amplia-se, nessa abordagem, a visão de que a inovação consiste em um processo localizado, incorporando influências do território local em que ocorre (Lastres et al., 1999;2003). Daí a aplicação das concepções de sistemas de inovação e redes de firmas também a territórios subnacionais: regionais e locais.

A incorporação da dimensão local do processo de inovação também está presente na abordagem do meio inovador, que, segundo Lecoq (1995:237), "elabora uma reflexão sobre o processo de territorialização das dinâmicas tecnológicas”. A abordagem do meio inovador também compartilha da idéia de que a inovação não se realiza, geralmente, de forma individual, e sim coletiva, necessitando da relação entre vários agentes, como também de fatores presentes no território. Nessa perspectiva, o meio inovador é visto como uma rede de relações sociais formais e informais, desenvolvida em uma área geográfica concreta, que propicia o desenvolvimento de sinergias e de processos de aprendizagem coletiva, sendo um elemento crucial no processo de inovação (Barroso, 1998:16).

Camagni (1995:197) assinala que os meios e redes territoriais, além da eficiência estática (redução dos custos de produção e transação), promovem uma eficiência dinâmica, que é gerada pela redução da incerteza nos processos de inovação e pela constituição de uma base relacional para o processo de aprendizagem coletiva.

Assim, essas abordagens alternativas trazem novos elementos para a compreensão do processo de inovação. A tecnologia é considerada endógena em relação ao processo de produção e ao território focalizado. A empresa não é concebida meramente como uma compradora de tecnologia, mas como detentora de uma capacidade de interferir e gerar mudança tecnológica.

Nesse contexto, o conceito de capacitação tecnológica, adquire particular importância. Hasenclever e Cassiolato (1998:310) definem a capacitação 
tecnológica como "o conjunto composto pela tecnologia, habilidades individuais e capacidades organizacionais", ou ainda, como "o conjunto de conhecimento codificado - explícito em normas, procedimentos e manuais - e de conhecimento tácito (implícito nas rotinas da empresa e na sua experiência acumulada) que um empresa domina”. Costa e Cunha (2001:268-69) relacionam a capacitação tecnológica com o "grau de controle que a empresa tem sobre o conjunto das tecnologias que lhe são úteis”. Assim, a capacitação tecnológica refere-se aos elementos que favorecem a capacidade da empresa de realizar o processo de inovação, concebido em sentido amplo: quanto ao processo produtivo, quanto ao produto e quanto à organização da produção.

Além disso, nessa nova concepção, há o reconhecimento de que o processo de inovação é interativo e localizado. Amplia-se a percepção de que a empresa está situada em um território e em uma rede de relações, que é necessária para constituir o processo de inovação. Dessa maneira, essas abordagens discutidas criticam tanto as abordagens "a-espaciais", que desconsideram o território em sua análise, quanto as abordagens que trabalham os processos de inovação como exógenos ou como subprodutos do processo de produção.

Em consonância com as novas concepçóes teóricas a respeito da inovação, os estudos empíricos e indicadores ligados à inovação também vêm passando por significativas transformações. Os estudos empíricos têm enfatizado, crescentemente, o conhecimento que a empresa domina, bem como as relaçóes externas estabelecidas pela empresa.

Desse modo, os autores que trabalham no âmbito dessas novas concepções a respeito da inovação procuram desenvolver indicadores que não se limitem ao âmbito da empresa individual, mas focalizem a rede em que elas se inserem para processo de inovação. Silva (2000:71), assinala que "os indicadores tradicionais sobre inovação, tais como gastos e pessoal empregado em P\&D pelas firmas e o número de patentes registradas, respondem apenas por uma parte dos processos nos quais pode surgir uma inovação".

Assim, percebe-se que está havendo uma mudança de ênfase nos estudos empíricos. Mais recentemente, vêm sendo priorizados indicadores relacionados à cooperação entre empresas, sendo importante captar as interações que ocorrem nesses processos. Esses indicadores, usualmente, são obtidos por meio de pesquisa primária, diretamente nas empresas. 
Pode-se citar, como exemplo desses novos estudos empíricos, os trabalhos de Yoguel e Boscherini (1996) e Boscherini et al. (1999), cuja concepção está fundamentada nas abordagens neo-schumpeteriana e do meio inovador, dentre outras. Esses autores desenvolveram uma metodologia que, com base em dados obtidos por meio de pesquisa direta nas empresas, busca caracterizar e dimensionar a capacidade inovativa das empresas, incorporando "a cooperação tecnológica entre agentes e o papel do espaço local no desenvolvimento da competência das firmas" (Boscherini et al., 1999:571).

O estudo empírico apresentado no presente trabalho baseia-se, em grande medida, na perspectiva e na metodologia desenvolvida por esses autores, embora o objetivo e a estrutura do estudo aqui discutido apresentem diferenças, o que requereu mudanças e adaptações na metodológicas. O principal objetivo do estudo empírico apresentado neste trabalho é caracterizar a capacitação tecnológica em um grupo de empresas localizadas em três cidades selecionadas, que ocupam posição de destaque na reconfiguração produtiva da rede urbana do Sudeste brasileiro. Em especial, procura-se dimensionar a importância do território local para a capacitação tecnológica das empresas, buscando captar as influências das características próprias de cada cidade e região sobre a capacitação tecnológica das empresas ali localizadas.

\section{Estrutura do estudo empírico e caracterização das cidades selecionadas: considerações metodológicas}

A elaboração do estudo empírico envolveu, fundamentalmente, os seguintes passos. Em primeiro lugar, foram selecionadas as três cidades; em seguida, foi feita a seleção das empresas. Posteriormente, aplicou-se um questionário em cada uma das empresas e, por fim, os resultados foram sistematizados e analisados. Essas etapas são sucintamente descritas nesta seção.

\subsection{As cidades selecionadas e sua estrutura produtiva}

Em primeiro lugar, buscou-se selecionar três cidades que cumprissem um papel relevante na rede urbana do Sudeste, em particular, no âmbito do processo de mudanças na concentração espacial que vem marcando a economia 
brasileira nas últimas décadas. ${ }^{1}$ Parte dessa bibliografia aponta que as cidades localizadas junto aos principais eixos rodoviários que ligam a Região Metropolitana de São Paulo (RMSP) a outros Estados (e outras regiōes metropolitanas) têm se destacado quanto ao crescimento econômico, em especial na indústria, adquirindo um papel proeminente na nova configuração territorial da produção. Destaque especial é dado para o entorno do Estado de São Paulo, ou seja, regiōes contíguas e próximas aos limites do Estado de São Paulo, em que se manifestam suas influências econômicas e urbanas.

Dessa maneira, selecionou-se uma cidade para cada um dos três eixos rodoviários considerados fundamentais nesse processo de reconfiguração territorial: 1) BR-050 (Anhanguera), que liga a RMSP ao Distrito Federal; 2) BR-381 (Fernão Dias), ligação entre RMSP e Região Metropolitana de Belo Horizonte; e 3) BR-116 (Via Dutra), que liga a RMSP à Região Metropolitana do Rio de Janeiro. A intenção foi trabalhar com cidades no entorno do Estado de São Paulo, isto é, municípios que se localizam fora desse Estado, mas relativamente próximos à divisa. Assim, pode-se considerar que as três cidades selecionadas sofrem certo grau de influência da RMSP, no âmbito das mudanças na concentração espacial e dos efeitos de dispersão, embora cada uma delas esteja situada em uma região com características urbanas e econômicas distintas, o que gera influências também distintas sobre a capacitação tecnológica das empresas em cada cidade.

Para a seleção das cidades, procurou-se estabelecer critérios que, combinados, privilegiassem municípios com razoável dimensão populacional e econômica, e que estivessem em trajetória de crescimento de sua participação no total de emprego do Brasil. Assim, para essa seleção, foram utilizados os seguintes critérios em relação aos municípios: i) localização próxima a eixos rodoviários que ligam a RMSP a outros Estados; ii) população entre 100.000 e 500.000 habitantes $^{2}$ (ou números próximos) em 1996; iii) número de empregados (RAIS) em 1995 acima de 15.000; e iv) crescimento da participação do município no total do emprego nacional entre 1985 e 1995 (crescimento acima das taxas nacionais) (RAIS).

1 O debate acerca das tendências recentes na concentração espacial das atividades produtivas tem marcado a bibliografia na área de economia regional nos últimos anos. Ver, por exemplo: Diniz, 1993; Pacheco, 1996; Andrade \& Serra, 2000.

2 Faixa intermediária de tamanho, denominada de "cidades médias" por parte da bibliografia. 
Com base nesses critérios, foram selecionadas três cidades para o estudo empírico: Uberlândia (MG), no eixo que liga a RMSP ao Distrito Federal; Pouso Alegre (MG), próximo à rodovia entre a RMSP e a RMBH; e Resende (RJ), posicionada no eixo RMSP-RMRJ.

\section{TABELA 1}

Municípios selecionados: população total e percentual do Brasil em 1991, 1996 e 2000, e distância do Município de São Paulo

\begin{tabular}{|c|c|c|c|c|c|c|c|}
\hline Município & $\begin{array}{l}\text { População } \\
\text { em } 1991\end{array}$ & $\begin{array}{l}\% \text { do } \\
\text { Brasil }\end{array}$ & $\begin{array}{c}\text { População } \\
\text { em } 1996\end{array}$ & $\begin{array}{l}\% \text { do } \\
\text { Brasil }\end{array}$ & $\begin{array}{c}\text { População } \\
\text { em } 2000\end{array}$ & $\begin{array}{l}\% \text { do } \\
\text { Brasil }\end{array}$ & $\begin{array}{c}\text { Distância de } \\
\text { São Paulo (km) }\end{array}$ \\
\hline Uberlândia & 367.061 & 0,214 & 438.986 & 0,253 & 501.214 & 0,284 & 603 \\
\hline Pouso Alegre & 81.836 & 0,048 & 93.166 & 0,054 & 106.776 & 0,061 & 205 \\
\hline Resende $^{3}$ & 91.757 & 0,054 & 102.625 & 0,059 & 104.549 & 0,059 & 254 \\
\hline
\end{tabular}

Fonte: IPEAData, IBGE, 2004 e Mapa Rodoviário do Brasil, 2000 (Ed. Abril).

Observa-se que os três municípios apresentaram crescimento da população em termos absolutos e também na participação em relação ao Brasil no período 1991/2000. Cada uma dessas cidades está situada em uma região com características distintas em relação à urbanização. Uberlândia está localizada no Triângulo Mineiro, composto por 35 municípios. Em comparação com as regiôes das outras duas cidades, há a presença de poucos centros urbanos, com participação expressiva de centros de médio e grande portes, em geral localizados com considerável distância entre si. Pouso Alegre situa-se no Sul de Minas, formado por 155 municípios, a maioria de pequeno porte, ainda que alguns alcancem um porte médio. $\mathrm{Na}$ maior parte dos casos, as sedes desses municípios estão a pequenas distâncias umas das outras. Resende localiza-se no sul fluminense, região situada entre as duas maiores metrópoles

3 Em 1997, houve o desmembramento do Município de Resende e a criação do Município de Porto Real. Em 2000, segundo o Censo Demográfico do IBGE, o Município de Porto Real contava com 12.095 habitantes, correspondente a $0,007 \%$ da população brasileira. 
do País e caracterizada pela presença de muitos centros urbanos. Destacamse os de médio porte, com razoável grau de industrialização, em geral, localizados próximos entre si (Fundação João Pinheiro e Fundação CIDE).

Quanto ao emprego, os números absolutos e a participação relativa de cada município no total do Brasil pode ser observado na Tabela 2.

TABELA 2

Emprego total e percentual do Brasil nos municípios selecionados em 1985, 1990, 1995, 2000 e 2003

\begin{tabular}{|c|c|c|c|c|c|c|c|c|c|c|}
\hline Município & 1985 & (\%) & 1990 & $\%$ & 1995 & $\%$ & 2000 & $\%$ & 2003 & $\%$ \\
\hline Uberlândia & 52.541 & 0,256 & 68.107 & 0,294 & 89.346 & 0,376 & 101.374 & 0,387 & 117.840 & 0,399 \\
\hline Pouso Alegre & 10.787 & 0,053 & 16.100 & 0,069 & 16.133 & 0,068 & 22.064 & 0,084 & 24.577 & 0,083 \\
\hline Resende 4 & 15.773 & 0,077 & 17.852 & 0,077 & 17.864 & 0,075 & 21.576 & 0,082 & 24.007 & 0,081 \\
\hline
\end{tabular}

Fonte: RAIS/TEM.

Nas duas tabelas apresentadas, observa-se que os dados referentes aos Municípios selecionados atendem aos critérios estabelecidos para a seleção de cidades, ${ }^{5}$ tanto em relação ao porte significativo, quanto em relação à trajetória de crescimento de sua participação no total do emprego no País.

A caracterização da evolução recente da estrutura produtiva das três cidades é realizada por meio de dados referentes ao emprego e ao PIB. As tabelas 3 e 4 apresentam a distribuição do emprego e do PIB de cada município selecionado entre os grandes setores econômicos.

4 O número de empregados de Porto Real foi de 1.963, em 2000; e 4.847, em 2003, correspondendo aos percentuais de 0,007 e 0,016 do total nacional, nesses mesmos anos.

5 Uma exceção foi o pequeno decréscimo da participação de Resende no total do emprego do Brasil entre 1985 e 1995, mas que foi significativamente revertido entre 1995 e 2000. 
TABELA 3

Distribuição do emprego por grandes setores econômicos nos municípios selecionados em 1985, 1990, 1995, 2000 e 2003 (\%)

\begin{tabular}{|c|c|c|c|c|c|}
\hline Ano & Agricultura & Indústria & Serviços & Outros / Ignorados & Total \\
\hline \multicolumn{6}{|c|}{ Uberlândia } \\
\hline 1985 & 4,12 & 22,24 & 72,52 & 1,12 & 100,00 \\
\hline 1990 & 5,53 & 22,04 & 67,31 & 5,12 & 100,00 \\
\hline 1995 & 4,87 & 22,32 & 71,99 & 0,82 & 100,00 \\
\hline 2000 & 5,39 & 21,73 & 72,88 & 0,00 & 100,00 \\
\hline 2003 & 4,30 & 19,96 & 75,74 & 0,00 & 100,00 \\
\hline \multicolumn{6}{|c|}{ Pouso Alegre } \\
\hline 1985 & 0,21 & 45,86 & 52,98 & 0,95 & 100,00 \\
\hline 1990 & 0,23 & 42,49 & 50,68 & 6,60 & 100,00 \\
\hline 1995 & 2,74 & 37,89 & 58,38 & 0,99 & 100,00 \\
\hline 2000 & 2,07 & 29,90 & 68,03 & 0,00 & 100,00 \\
\hline 2003 & 2,52 & 29,95 & 67,53 & 0,00 & 100,00 \\
\hline \multicolumn{6}{|c|}{ Resende $^{6}$} \\
\hline 1985 & 1,43 & 39,89 & 58,37 & 0,31 & 100,00 \\
\hline 1990 & 2,31 & 35,53 & 55,61 & 6,55 & 100,00 \\
\hline 1995 & 4,95 & 29,27 & 65,41 & 0,38 & 100,00 \\
\hline 2000 & 1,95 & 24,56 & 73,49 & 0,00 & 100,00 \\
\hline 2003 & 1,42 & 17,35 & 81,23 & 0,00 & 100,00 \\
\hline
\end{tabular}

Fonte: RAIS/TEM.

6 Para Porto Real, a distribuição foi a seguinte. No ano 2000, Agricultura $(0,66)$, Indústria $(53,34)$ e Serviços $(46,00)$; e, em 2003, Agricultura $(0,85)$, Indústria $(64,82)$ e Serviços $(34,33)$. 
TABELA 4

Distribuição do PIB por grandes setores econômicos nos municípios selecionados em 1980, 1985, 1996, 2000 e 2003 (\%)

\begin{tabular}{lcccc}
\hline Ano & Agropecuária & Indústria & Serviços & Total \\
\hline & Uberlândia & \\
\hline 1980 & 3,61 & 36,99 & 59,40 & 100,00 \\
1985 & 4,80 & 26,49 & 68,71 & 100,00 \\
1996 & 3,74 & 45,90 & 50,36 & 100,00 \\
2000 & 3,41 & 42,52 & 54,07 & 100,00 \\
2003 & 3,97 & 43,62 & 52,40 & 100,00
\end{tabular}

\section{Pouso Alegre}

\begin{tabular}{llccc}
1980 & 3,79 & 55,14 & 41,07 & 100,00 \\
1985 & 5,01 & 52,76 & 42,23 & 100,00 \\
1996 & 2,10 & 51,00 & 46,90 & 100,00 \\
2000 & 1,67 & 49,34 & 48,99 & 100,00 \\
2003 & 1,98 & 46,95 & 51,07 & 100,00 \\
\hline & & & & \\
\hline 1980 & & & & 100,00 \\
1985 & 4,08 & 62,60 & 33,32 & 100,00 \\
1996 & 2,13 & 40,26 & 57,60 & 100,00 \\
2000 & 2,04 & 52,35 & 45,61 & 100,00 \\
2003 & 0,58 & 67,93 & 31,49 & 100,00
\end{tabular}

Fonte: IPEAData (para os anos de 1980, 1985 e 1996) e IBGE (para os anos de 2000 e 2003).

7 As participações de Porto Real foram, em 2000, de 0,51\% na Agropecuária; de 73,74 \% na Indústria; e de 25,75\% nos Serviços; e, em 2003, corresponderam a 0,07\% na Agropecuária; a 80,34\% na Indústria; e a 19,59\% nos Serviços. 
Observa-se que as cidades mostram diferentes perfis em relação à estrutura produtiva no período recente: Uberlândia apresenta um perfil voltado para o setor terciário, que tem grande peso nos dois tipos de dados. Pouso Alegre possui um perfil mais industrial, pois esse setor apresenta uma grande participação tanto no número de empregos quanto no PIB. Resende ocupa uma posição intermediária, ${ }^{8}$ com maior participação do terciário no emprego, em patamares próximos aos de Uberlândia, e maior participação da indústria no PIB, atingindo percentuais acima dos apresentados pela indústria de Pouso Alegre.

Simultaneamente a essas diferenças no perfil da estrutura produtiva, verifica-se uma característica comum aos três municípios: esses apresentam uma razoável diversificação produtiva, com pequena participação da agricultura nos dois tipos de dados. Assim, considerando os grandes setores econômicos, verifica-se que nos municípios selecionados há pouca especialização setorial, embora haja diferentes composições setoriais para cada município nos dois tipos de dados analisados.

Assim, percebe-se que as três cidades estão localizadas em regióes polarizadas pela RMSP, o que as coloca sob influência de um processo de desconcentração das atividades produtivas da RMSP ocorrido no período recente. Essas regiōes apresentam diferenças marcantes quanto ao padrão de urbanização. As três cidades são caracterizadas pela diversificação produtiva, mas também mostram diferenças significativas quanto à sua estrutura produtiva e quanto à distância da RMSP.

Dessa maneira, espera-se que as características distintas dessas cidades e suas regiões, em especial quanto à urbanização e à estrutura produtiva, representem influências também distintas sobre a capacitação tecnológica das empresas localizadas em cada uma das cidades.

\subsection{A seleção das empresas para a pesquisa de campo}

Na seleção das empresas para aplicação dos questionários, partiu-se de uma caracterização setorial da indústria de cada cidade, levando em conta, sobretudo, a participação de cada segmento industrial no emprego, destacando os de maior participação. Em seguida, foram selecionadas duas empresas para cada segmento, procurando-se trabalhar, quando possível, com uma empresa grande

8 Mesmo com a emancipação de Porto Real, que, conforme mostram os dados, tem um perfil concentrado na indústria, esse perfil de Resende confirma-se nos dois últimos anos da série. 
e uma pequena para cada segmento, de maneira a captar também diferenças de resultados ligadas ao tamanho da empresa. Foram privilegiadas as empresas de capital local.

Seguindo esse critérios, foram destacados três segmentos industriais em cada cidade e selecionadas duas empresas para cada segmento, definindo, portanto, uma "amostra intencional", que busca privilegiar os segmentos mais importantes e o capital local e, simultaneamente, garantir certa diversidade (evitar especializações) quanto aos tamanhos e aos segmentos. Como a pesquisa focaliza o período 1995/2000, o ano de 1997 foi utilizado como base para a seleção dos segmentos industriais para o estudo empírico. O número de empregados por segmento em 1997, nas três cidades selecionadas, pode ser observado na Tabela 5.

Os dados relativos aos segmentos industriais, em 1997, revelam distintas estruturas industriais para as três cidades. Em Uberlândia, os segmentos industriais com maior proporção do número de empregados são os de "Produtos Alimentares, Bebidas e Álcool Etílico" e depois "Borracha, Fumo, Couros, Peles, Similares e Diversos". Em uma faixa intermediária estão os segmentos "Indústria Metalúrgica", "Indústria Têxtil, do Vestuário e Artefatos de Tecidos" e "Papel, Papelão, Editorial e Gráfica”, enquanto os demais possuem uma menor participação. Em Pouso alegre os segmentos com maiores percentuais são os de "Indústria Química, de Produtos Farmacêuticos, Veterinários e Perfumaria" e "Produtos Alimentares, Bebidas e Álcool Etílico", seguidos, em ordem decrescente, por "Material de Transporte", "Têxtil, do Vestuário e Artefatos de Tecidos" e "Indústria Metalúrgica". Em Resende, ocorre a maior proporção no segmento de "Indústria Mecânica", seguido, por "Indústria Química, de Produtos Farmacêuticos, Veterinários e Perfumaria", "Produtos Alimentares, Bebidas e Álcool Etílico”, "Minerais não-metálicos” e, em menor grau, pelos de "Material de Transporte" e "Indústria Metalúrgica".

Como característica comum das três cidades, verifica-se que os segmentos "Produtos Alimentares, Bebidas e Álcool Etílico" e "Indústria Metalúrgica" alcançam proporções significativas (entre 5,99 e 37,30\% da indústria de transformação). Essa característica levou à seleção desses segmentos para o estudo empírico, de modo a facilitar comparações entre os resultados. Além disso, a seleção de mesmos segmentos para as três cidades evita que comportamentos específicos do segmento industrial, sejam interpretados como devidos à localização. 
TABELA 5

Número de empregados e distribuição percentual por segmento da indústria de transformação nos municípios de Uberlândia, Pouso Alegre e Resende em 1997

\begin{tabular}{|c|c|c|c|c|c|c|}
\hline \multirow{2}{*}{ Segmentos } & \multicolumn{2}{|c|}{ Uberlândia } & \multicolumn{2}{|c|}{ Pouso Alegre } & \multicolumn{2}{|c|}{ Resende } \\
\hline & $n^{\circ}$ & $\%$ & $n^{\circ}$ & $\%$ & $n^{\circ}$ & $\%$ \\
\hline Produtos Minerais não-Metálicos & 419 & 3,01 & 124 & 2,17 & 701 & 15,45 \\
\hline Indústria Metalúrgica & 1.065 & 7,65 & 610 & 10,70 & 272 & 5,99 \\
\hline Indústria Mecânica & 175 & 1,25 & 28 & 0,49 & 1.200 & 26,45 \\
\hline Material Elétrico e de Comunicações & 253 & 1,81 & 280 & 4,91 & 0 & 0,00 \\
\hline Material de Transporte & 359 & 2,57 & 932 & 16,35 & 453 & 9,98 \\
\hline Madeira e do Mobiliário & 324 & 2,32 & 27 & 0,47 & 29 & 0,63 \\
\hline Papel, Papelão, Editorial e Gráfica & 875 & 6,28 & 102 & 1,78 & 30 & 0,66 \\
\hline Borracha, Fumo, Couros, Peles, Simil.,Div. & 3.076 & 22,10 & 55 & 0,96 & 130 & 2,86 \\
\hline Ind. Química, de Prod. Farm., Veter., Perf. & 494 & 3,54 & 1.316 & 23,09 & 875 & 19,29 \\
\hline Ind. Têxtil, do Vest. e Artefatos de Tecidos & 1.277 & 6,12 & 725 & 12,72 & 92 & 2,02 \\
\hline Calçados & 407 & 2,92 & 157 & 2,75 & 0 & 0,00 \\
\hline Prod. Aliment., Bebidas e Álcool Etílico & 5.192 & 37,30 & 1.343 & 23,56 & 754 & 16,62 \\
\hline Total Indústria de Transformação & 13.916 & 100,00 & 5.699 & 100,00 & 4.536 & 100,00 \\
\hline
\end{tabular}

Fonte: Ministério do Trabalho e Emprego/Relação Anual de Informações Sociais (RAIS). 
Foi escolhido ainda um terceiro segmento para cada cidade, considerando a proporção no número de empregados. Assim, foram selecionados para o estudo, os segmentos de "Indústria Química, de Produtos Farmacêuticos, Veterinários e Perfumaria" para Pouso Alegre e de "Indústria Mecânica" para Resende, que constituem os segmentos de maior proporção de empregados na indústria de transformação nessas cidades. Em Pouso Alegre, a participação do segmento de "Indústria Química, de Produtos Farmacêuticos, Veterinários e Perfumaria” (23,09\%) praticamente se equivale à do segmento de "Produtos Alimentares, Bebidas e Álcool Etílico" (23,56\%), que foi selecionado nas três cidades. Em Uberlândia, o segmento de maior participação, "Produtos Alimentares, Bebidas e Álcool Etílico", já havia sido selecionado para as três cidades. Optou-se por trabalhar, então, com o segmento de Material Elétrico que, embora não esteja entre os de maior participação no número de empregados, possui dois casos interessantes de empresas de capital local, um dos critérios para a seleção de empresas.

Em seguida, procedeu-se à seleção de duas empresas em cada segmento, considerando, basicamente, os dois critérios já mencionados. Em primeiro lugar, optou-se por selecionar sempre uma empresa grande e a outra pequena, em relação ao número de empregados, para cada segmento, embora, como pode ser observado na Tabela 6 , a classificação por tamanho não obedeceu a critérios rígidos e variou entre os segmentos industriais. Esse procedimento permite observações acerca da relação entre o tamanho das firmas e os resultados apresentados quanto à capacitação tecnológica.

Como segundo critério, foi dada preferência às empresas de capital local, ou seja, da cidade onde estão instaladas. Entende-se que essas empresas tendem a explicitar melhor as relações com o território e sua importância para a capacitação tecnológica. Para a seleção das empresas, foram utilizadas informações obtidas junto a seus órgãos de representação, a Federação das Indústrias do Estado de Minas Gerais (FIEMG) e Federação das Indústrias do Estado do Rio de Janeiro (FIRJAN), sobretudo em suas páginas na internet.

Assim, para cada cidade foram selecionadas seis empresas, perfazendo um total de dezoito empresas selecionadas ${ }^{9}$ para pesquisa:

\footnotetext{
9 As empresas são, na sua maior parte, de capital local, ou seja, da cidade em que estão instaladas (são 13 de capital local e cinco de outras cidades: três de São Paulo, uma do Rio de Janeiro e uma do interior de São Paulo). A maior parte (dois terços) foi instalada entre 1988 e 1997, e a totalidade produz para o mercado interno brasileiro, vendendo para diversos compradores (com exceção de uma, que mantém uma única empresa compradora).
} 
TABELA 6

Empresas pesquisadas: segmento industrial e número de empregados

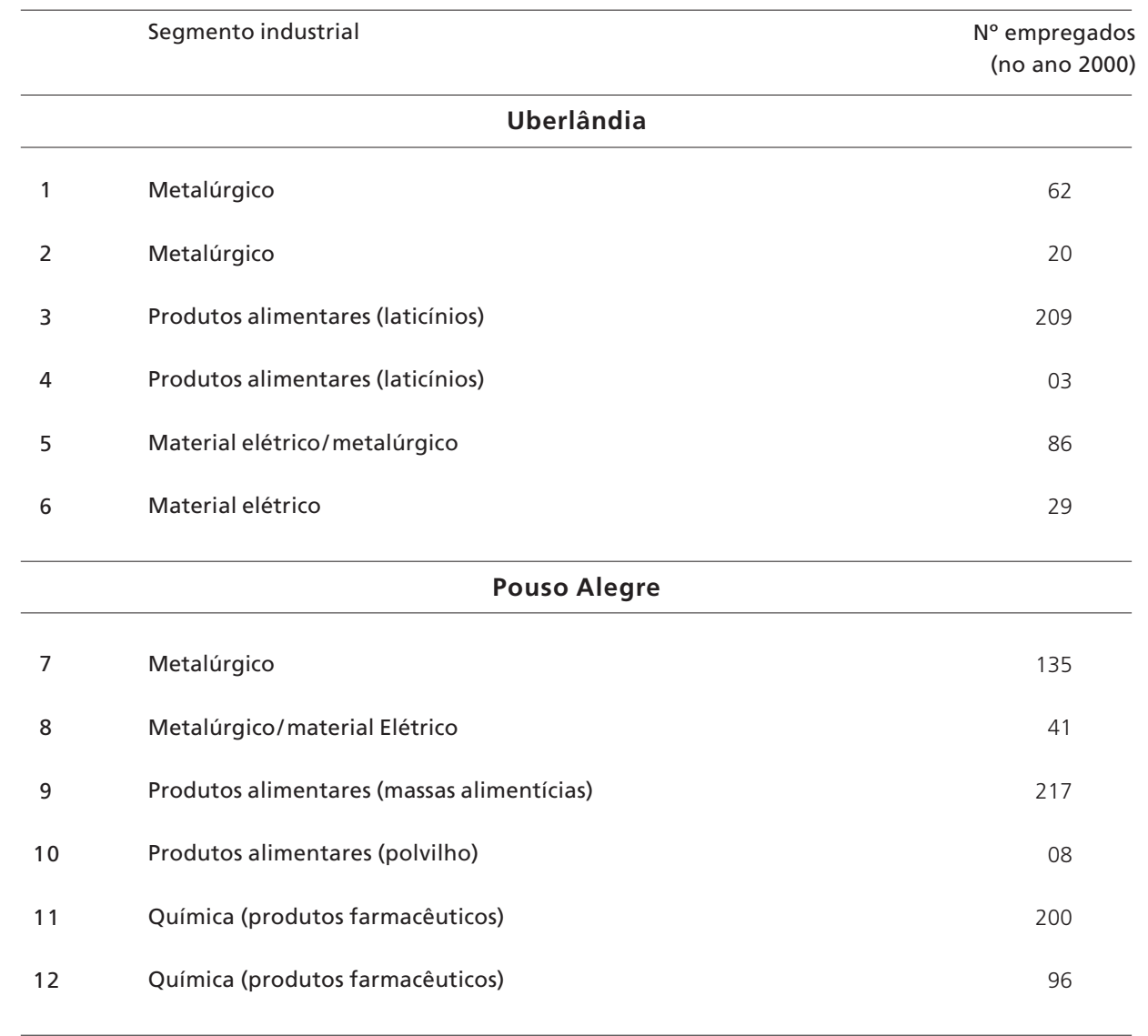

\section{Resende}

13

Metalúrgico

$14 \quad$ Metalúrgico

15 Produtos alimentares (laticínios)

40

16

Produtos alimentares (laticínios)

17 Mecânico

100

18

Mecânico

10

Fonte: Pesquisa de Campo e Seleção realizadas pelo autor, com base em informações fornecidas pela FIEMG e FIRJAN. 
Dessa maneira, o conjunto das empresas pesquisadas não constitui uma amostra estatisticamente representativa, mas uma "amostra intencional", selecionada segundo critérios definidos previamente, nos quais a participação do segmento na indústria do município, em termos de emprego, cumpre papel fundamental.

\subsection{0 questionário aplicado}

O estudo empírico foi realizado por meio de pesquisa direta nas empresas selecionadas, com realização de entrevistas e aplicação de questionários em que são tratadas questóes referentes à capacidade inovativa, às fontes de conhecimento e às práticas de terceirização presentes no processo produtivo. Os questionários aplicados eram "fechados": as respostas eram sugeridas, de maneira que o entrevistado optava dentre algumas alternativas, conforme metodologia adotada.

Como já mencionado, a metodologia utilizada neste trabalho baseia-se, em larga medida, nos trabalhos de Boscherini e Yoguel (1996) e Boscherini et al. (1999), em especial no Índice de Capacidade Inovativa (ICI), índice que combina aspectos relacionados à capacitação tecnológica da empresa e vínculos por ela estabelecidos com outras empresas e instituiçóes, com destaque para o ambiente local. ${ }^{10}$ As variáveis que compóem o ICI, bem como as principais questôes relacionadas a elas, são apresentadas no Quadro 1.

As variáveis de 1 a 6 tratam de aspectos da capacitação tecnológica das empresas considerados isoladamente. Já as variáveis de 7 a 9 possuem um caráter mais sintético e constituem índices elaborados mediante a combinação de diversos dados obtidos na pesquisa. Assim, a obtenção dessas últimas variáveis, de acordo com parâmetros presentes nos trabalhos dos autores, envolve a combinação de diversas informações para obter um resultado mais abrangente.

Para cada variável, é organizada uma distribuição por classes, com a construção de quatro classes, correspondendo a quatro níveis de intensidade. A construção das classes é feita mediante o seguinte processo, indicado pelos autores do questionário: toma-se a diferença entre o valor máximo e o valor

\footnotetext{
10 O autor agradece a Gabriel Yoguel pelo envio de um questionário utilizado em suas pesquisas, que serviu de base para a construção do questionário aplicado nas empresas selecionadas neste trabalho.
} 


\section{QUADRO 1}

Variáveis que compõem o Índice de Capacidade Inovativa e principais questões relacionadas

\section{Nome}

1 Esforço de capacitação de pessoal

2 Atividades vinculadas à qualidade

3 Participação de engenheiros e técnicos nas atividades inovativas

$4 \quad$ Grau de envolvimento dos operários nas tarefas de qualidade

5 Peso dos novos produtos no faturamento

6 Grau de continuidade e estabilidade dos recursos humanos ligados à atividade inovativa

7 Grau de alcance das atividades de desenvolvimento

8 Índice de cooperação tecnológica

9 Importância do ambiente local

\section{Principais Questões}

Percentual de empregados que participaram de cursos orientados para qualidade e atividades de desenvolvimento

Utilização de técnicas de organização da produção, indicadores de desempenho e controle de qualidade

Percentual de engenheiros e técnicos no total de pessoal envolvido nas atividades inovativas

Participação dos operários no controle de qualidade e nas atividades de desenvolvimento

Percentual do faturamento, no ano anterior à pesquisa, correspondente aos produtos introduzidos no período focalizado

Grau de continuidade das atividades inovativas e grau de estabilidade das equipes responsáveis

Número de áreas em que a empresa realiza desenvolvimentos, número de engenheiros e técnicos e grau de exclusividade de pessoal envolvido em atividades de inovação

Relações com outras empresas ou instituições para desenvolvimento de produtos e processos (número, freqüência, período e grau de formalização dessas relações)

Fontes de informação e número de instituições no ambiente local, localização das empresas e instituições com as quais a empresa interage, difusão de conhecimento via trabalhadores especializados e difusão de informações via conversas informais

Fonte: Elaboração do autor, com base em Yoguel \& Boscherini (1996) e Boscherini et al. (1999). 
mínimo encontrados, divide-se essa diferença por quatro, e utiliza-se o valor encontrado como intervalo para distribuir as firmas pelas classes.

O valor do ICI é calculado pela soma ponderada dessas nove variáveis. Nessa perspectiva, os autores propõem-se a construir um indicador que "permita efetuar comparaçóes entre casos e, portanto, possa ser definido em termos absolutos e não relativos" (Boscherini et al., 1999:571).

O presente trabalho utiliza como base o questionário e o sistema de organização em classes de alguns resultados ligados ao ICI, desenvolvidos por esses autores. No entanto, embora a perspectivas e os objetivos dos autores tenham pontos de contato com o presente trabalho, algumas diferenças podem ser identificadas: busca-se, neste trabalho, caracterizar a capacitação tecnológica em um grupo de empresas localizadas em três cidades selecionadas, com vistas a avaliar a importância do território local, sem, entretanto, procurar obter um valor final para um índice quantitativo, que possa ser usado para comparação entre cidades. $\mathrm{O}$ mais importante, neste trabalho, é dimensionar a importância do território local para a capacitação tecnológica das empresas e avaliar se empresas localizadas em diferentes cidades, mesmo de setores e portes semelhantes, revelam especificidades e características distintas quanto à capacitação tecnológica.

Assim, no presente trabalho, a organização e a interpretação dos resultados cumprem uma diferente racionalidade: em vez da soma ponderada das variáveis, como ocorre na metodologia original do ICI, em que é gerado um resultado numérico, optou-se por apresentar a distribuição das empresas por classes, segundo cada variável e, posteriormente, em conjunto com questóes mais específicas do território, proceder a uma avaliação global dos resultados, com caráter qualitativo.

Dessa forma, algumas mudanças significativas foram realizadas para adaptar o questionário original do ICI, bem como a organização dos resultados, aos propósitos deste trabalho. Primeiramente, houve uma seleção das perguntas presentes no questionário, destacando aquelas que cumpriam papel relevante quanto à capacitação tecnológica, à importância do território e às fontes de conhecimento. Em seguida, foram acrescentadas algumas questões específicas relacionadas às práticas de terceirização utilizadas pelas empresas. Além disso, este estudo empírico busca analisar qualitativamente os processos em discussão. Assim, embora tenha sido feito um esforço de traduzir quantitativamente algumas questôes, os resultados são sempre analisados com uma 
ótica qualitativa, em que o posicionamento ordinal dos resultados é mais importante, como será mostrado na próxima seção.

No questionário, além das perguntas referentes às variáveis que compõem o ICI, foram incluídas duas questões que tratam de outros aspectos importantes relacionados à inovação e à capacitação tecnológica. A primeira refere-se às fontes de aquisição de conhecimento por parte da empresa, fundamentais para a realização das atividades inovativas .

Também foi incluída uma questão sobre ocorrência de terceirização no processo produtivo, que se refere às práticas, permanentes e regulares, em que parte do processo produtivo é realizada por outra empresa. Parte da bibliografia assinala que terceirização pode constituir um importante mecanismo de estímulo à produtividade e à inovação, à medida que permite à empresa focar no seu core business e transferir algumas atividades para outras empresas, especialmente as mais rotineiras e de menor qualificação (Britto, 2002; Druck, 1999; Carleial, 1997).

Os questionários foram aplicados nos meses de setembro e novembro de 2000 , sendo que as questôes referiam-se a atividades desenvolvidas ao longo do período 1995/2000.

\section{Capacidade inovativa, fontes de conhecimento e terceirização do processo produtivo: resultados do estudo empírico}

A apresentação dos resultados é realizada na seguinte seqüência. Primeiramente, são apresentados os resultados ligados às variáveis que compõem o Índice de Capacidade Inovativa (ICI). Em seguida, são destacados os resultados relacionados às fontes de conhecimento utilizadas pelas empresas para realizar os desenvolvimentos apontados. Por fim, são apresentados resultados acerca das práticas de terceirização implementadas pelas empresas.

\subsection{Resultados referentes às variáveis que compõem o ICI}

As tabelas 7, 8, 9, 10, 11 e 12 apresentam, para cada variável, os resultados para o conjunto de empresas pesquisadas, bem como os resultados das empresas por cidade. Elas também mostram a distribuição percentual das empresas segundo as classes, correspondendo aos níveis de intensidade de cada variável. 
TABELA 7

Esforço de capacitação de pessoal: distribuição percentual das empresas por classe

\begin{tabular}{lcccc}
\hline & Conjunto & Uberlândia & Pouso Alegre & Resende \\
Elevado & 22,22 & 16,66 & 33,33 & 16,66 \\
Mediano & 16,66 & - & 50,00 & - \\
Reduzido & 11,11 & 16,66 & - & 16,66 \\
Muito reduzido & 50,00 & 66,66 & 16,66 & 66,66 \\
Total & 100,00 & 100,00 & 100,00 & 100,00 \\
\hline
\end{tabular}

Fonte: pesquisa de campo realizada pelo autor.

A distribuição dessa variável em classes mostrou que metade das empresas pesquisadas efetiva Esforço de capacitação de pessoal em nível considerado muito reduzido, enquanto a outra metade está distribuída nas outras classes, com destaque para a classificação "elevado", revelando certa concentração nas classes extremas ("elevado" e "muito reduzido").

As empresas de Pouso Alegre mostraram maior concentração nas primeiras classes do que a média, enquanto as empresas de Resende e Uberlândia revelaram comportamentos equivalentes.

\section{TABELA 8}

Atividades vinculadas à qualidade: distribuição percentual das empresas por classe

\begin{tabular}{|c|c|c|c|c|}
\hline & Conjunto & Uberlândia & Pouso Alegre & Resende \\
\hline Elevado & 38,88 & 16,66 & 66,66 & 33,33 \\
\hline Mediano & 22,22 & 50,00 & - & 16,66 \\
\hline Reduzido & 33,33 & 33,33 & 33,33 & 33,33 \\
\hline Muito reduzido & 05,55 & - & - & 16,66 \\
\hline Total & 100,00 & 100,00 & 100,00 & 100,00 \\
\hline
\end{tabular}

Fonte: pesquisa de campo realizada pelo autor. 
TABELA 9

Participação de engenheiros e técnicos nas atividades inovativas: distribuição percentual das empresas por classe

\begin{tabular}{lcccc}
\hline & Conjunto & Uberlândia & Pouso Alegre & Resende \\
Elevado & 33,33 & 16,66 & 50,00 & 33,33 \\
Mediano & 11,11 & 33,33 & - & - \\
Reduzido & 16,66 & - & 33,33 & 16,66 \\
Muito reduzido & 38,88 & 50,00 & 16,66 & 50,00 \\
Total & 100,00 & 100,00 & 100,00 & 100,00 \\
\hline
\end{tabular}

Fonte: pesquisa de campo realizada pelo autor.

Essa variável está distribuída de forma bem mais estratificada, ocupando as três primeiras classes, sobretudo a primeira e a terceira, mostrando que a quase totalidade das empresas realiza alguma atividade vinculada à qualidade.

As empresas de Pouso Alegre foram as que mostraram maior concentração na classe "elevada", seguidas pelo grupo de empresas de Uberlândia. As empresas pesquisadas de Resende estão distribuídas de forma mais equilibrada entre as classes estabelecidas.

TABELA 10

Grau de envolvimento dos operários nas tarefas de qualidade: distribuição percentual das empresas por classe

\begin{tabular}{lcccc}
\hline & Conjunto & Uberlândia & Pouso Alegre & Resende \\
Elevado & 72,22 & 50,00 & 100,00 & 66,66 \\
Mediano & 16,66 & 50,00 & - & - \\
Reduzido & 11,11 & - & - & 33,33 \\
Muito reduzido & - & - & - & - \\
Total & 100,00 & 100,00 & 100,00 & 100,00 \\
\hline
\end{tabular}

Fonte: pesquisa de campo realizada pelo autor. 
TABELA 11

Peso dos novos produtos no faturamento: distribuição percentual das empresas por classe

\begin{tabular}{lcccc}
\hline & Conjunto & Uberlândia & Pouso Alegre & Resende \\
Elevado & 22,22 & - & 50,00 & 66,66 \\
Mediano & - & - & - & - \\
Reduzido & 11,11 & - & - & 33,33 \\
Muito reduzido & 66,66 & 100,00 & 50,00 & 33,33 \\
Total & 100,00 & 100,00 & 100,00 & 100,00 \\
\hline
\end{tabular}

Fonte: pesquisa de campo realizada pelo autor.

A distribuição dessa variável em classes mostrou certa concentração nas classes extremas (participação elevada e muito reduzida).

Dentre as cidades, as empresas de Pouso Alegre mostraram maior concentração nas primeiras classes do que a média, enquanto as empresas pesquisadas de Resende e Uberlândia manifestaram comportamentos equivalentes, similar ao que ocorre na próxima variável.

Para o conjunto das empresas, a distribuição dessa variável em classes mostrou um alto grau de envolvimento dos operários nas tarefas de qualidade: $72 \%$ das empresas estão posicionadas na primeira classe, apresentando um elevado grau de envolvimento.

Percebe-se que, para dois terços das empresas, o peso dos novos produtos no faturamento é muito pequeno, correspondendo à última classe. Contudo, para cerca de um quarto delas esse peso é grande, revelando certa concentração nas classes extremas (elevado e muito reduzido).

Nessa variável, observa-se um comportamento muito diferenciado entre as cidades. As empresas de Pouso Alegre mostraram maior concentração nas primeira e última classes, enquanto a distribuição das empresas de Resende foi estratificada e as de Uberlândia estiveram concentradas na última classe.

Essa variável apresentou uma concentração das empresas nas classes intermediárias (graus mediano e reduzido), embora uma parcela significativa tenha apresentado um grau elevado. 
TABELA 12

Grau de continuidade e estabilidade dos recursos humanos ligados à atividade inovativa: distribuição percentual das empresas por classe

\begin{tabular}{lcccc}
\hline & Conjunto & Uberlândia & Pouso Alegre & Resende \\
Elevado & 22,22 & 33,33 & 33,33 & - \\
Mediano & 38,88 & - & 50,00 & 66,66 \\
Reduzido & 33,33 & 50,00 & 16,66 & 33,33 \\
Muito reduzido & 05,55 & 16,66 & - & 100,00 \\
\hline Total & 100,00 & 100,00 & 100,00 & - \\
\hline
\end{tabular}

Fonte: pesquisa de campo realizada pelo autor.

Mais uma vez, as empresas de Pouso Alegre pesquisadas alcançaram maior concentração nas primeiras classes enquanto a distribuição das empresas de Uberlândia (mais estratificada) e das empresas de Resende (mais concentrada no grau mediano) tenderam a equivaler-se.

As próximas três variáveis, conforme já explicitado, tratam de aspectos mais abrangentes referentes à capacitação tecnológica e são obtidas pela combinação de vários resultados, por isso, chamadas de variáveis-síntese. Entretanto, em vez de trabalhar com um resultado final nessas variáveis, como na metodologia original do ICI, optou-se, neste trabalho, por mostrar individualmente os resultados referentes aos indicadores que compóem essas variáveis, de maneira que cada indicador pudesse ser analisado separadamente.

Os indicadores referentes ao Grau de alcance das atividades de desenvolvimento são examinados na Tabela 13 .

Essa variável está relacionada à importância que a atividade inovativa tem no âmbito da empresa. Os resultados referentes aos indicadores que compóem o Grau de alcance das atividades de desenvolvimento podem ser considerados razoáveis: o número de áreas em que a empresa efetua a inovação; bem como a participação de engenheiros e técnicos no pessoal envolvido em atividades inovativas apresentam resultados razoáveis, mostrando diversificação entre os tipos de atividades ligadas à inovação e importância da formação técnica do pessoal que desenvolve atividades inovativas na empresa. Já o grau 
TABELA 13

Indicadores referentes ao Grau de Alcance das Atividades de Desenvolvimento (média por empresa)

\begin{tabular}{lcccc}
\hline & Conjunto & Uberlândia & Pouso Alegre & Resende \\
$\begin{array}{l}\text { Número de áreas em que a empresa } \\
\text { realiza inovação (1 a 6)* }\end{array}$ & 4,16 & 4,33 & 4,66 & 3,50 \\
$\begin{array}{l}\text { Percentual de engenheiros e técnicos no } \\
\text { pessoal envolvido em atividades inovativas }\end{array}$ & 47,43 & 36,66 & 61,14 & 44,50 \\
$\begin{array}{l}\text { Percentual de exclusividade do pessoal } \\
\text { envolvido em atividades inovativas }\end{array}$ & 38,78 & 27,16 & 41,74 & 47,46 \\
& & & & \\
\hline
\end{tabular}

* Novos produtos; melhorias de produtos; novos processos; melhorias de processos; introdução ou melhoria de formas organizacionais; novas formas de distribuição e marketing.

Fonte: pesquisa de campo realizada pelo autor.

de exclusividade desse pessoal, indicado pela proporção de pessoas dedicadas a maior parte do tempo às atividades inovativas, dentre as que desenvolvem essas atividades, revela-se reduzido: cerca de $38 \%$ no conjunto das empresas.

Entre as cidades, Pouso Alegre apresenta os melhores resultados para os dois primeiros indicadores, embora seja superada por Resende quanto ao grau de exclusividade do pessoal envolvido nas atividades inovativas.

As tabelas 14 e 15 tratam dos indicadores referentes ao Índice de Cooperação Tecnológica.

\section{TABELA 14}

Indicadores referentes ao Índice de Cooperação Tecnológica: número de relações com outras empresas ou instituições para desenvolvimento de produtos e processos e número de agentes (média por empresa)

\begin{tabular}{lcccc} 
& Conjunto & Uberlândia & Pouso Alegre & Resende \\
Número de relações (vínculos) & 2,99 & 3,16 & 3,00 & 2,83 \\
Número de agentes & 1,72 & 1,50 & 2,16 & 1,50 \\
\hline
\end{tabular}

Fonte: pesquisa de campo realizada pelo autor. 
TABELA 15

Indicadores referentes ao Índice de Cooperação Tecnológica: freqüência, complexidade e formalização das relações com outras empresas ou instituições para desenvolvimento de produtos e processos (\%)

\begin{tabular}{|c|c|c|c|c|}
\hline & Conjunto & Uberlândia & Pouso Alegre & Resende \\
\hline \multicolumn{5}{|l|}{ Freqüência } \\
\hline Esporádica & 29,62 & 27,77 & 17,64 & 42,10 \\
\hline Trimestral & 05,55 & 0 & 11,76 & 05,26 \\
\hline Mensal, semanal ou diária & 64,81 & 72,22 & 70,58 & 63,15 \\
\hline \multicolumn{5}{|l|}{ Complexidade } \\
\hline Complementar competências técnicas & 44,32 & 34,48 & 56,66 & 42,10 \\
\hline Obter economias de escala & 55,67 & 65,51 & 43,33 & 57,89 \\
\hline \multicolumn{5}{|l|}{ Formalização } \\
\hline Formal & 57,53 & 64,61 & 47,05 & 60,95 \\
\hline Informal & 42,46 & 35,39 & 52,94 & 39,05 \\
\hline
\end{tabular}

Fonte: pesquisa de campo realizada pelo autor.

Essa variável está relacionada à importância que os vínculos externos à empresa têm para sua atividade inovativa. A cooperação tecnológica, considerada em sentido amplo, é avaliada por vários indicadores. Embora o número de vínculos externos estabelecidos pela empresa e o número de agentes envolvidos nessas relações possam ser considerados baixos para o conjunto de empresas, o exame das características desses vínculos revela que eles certamente constituíram importantes mecanismos para o desenvolvimento da capacidade inovativa das empresas.

A freqüência dessas relaçōes é, predominantemente, intensa: quase dois terços foram classificados como mensal, semanal, ou diária. Quanto à complexidade dessas relaçôes, embora a maior parte tenha sido utilizada para obter economias de escala (ligadas a processos rotineiros), parte significativa esteve voltada para complementar competências técnicas (voltadas a atividades inovativas). Em relação à formalidade, a maior parte dessas relações esteve formalizada. 
Verifica-se que, dentre as cidades, Uberlândia apresenta os melhores resultados quanto ao número de relações, sua freqüência e formalização, enquanto Pouso Alegre mostra resultados melhores em relação ao número de agentes e à complexidade das relações estabelecidas.

As tabelas 16 e 17 referem-se à Importância do Ambiente Local para a capacidade inovativa da empresa.

\section{TABELA 16}

Indicadores referentes à Importância do Ambiente Local: tipos de informações sobre produtos, processos e mercados; número de empresas e instituições na região que disponibilizam informações; e participação das empresas e instituições locais nas interações da empresa (média por empresa)

\begin{tabular}{|c|c|c|c|c|}
\hline & Conjunto & Uberlândia & Pouso Alegre & Resende \\
\hline Tipos de informações (1 a 18)* & 05,50 & 06,66 & 05,66 & 04,16 \\
\hline Número de agentes & 03,05 & 03,16 & 03,33 & 02,66 \\
\hline Participação local nas interações & 43,14 & 58,22 & 50,27 & 20,83 \\
\hline
\end{tabular}

Fonte: pesquisa de campo realizada pelo autor.

Essa variável está relacionada à importância que o ambiente local tem para a atividade inovativa da empresa. A importância do ambiente local é avaliada mediante vários elementos. A diversidade de informações disponíveis na região em que a empresa se localiza; o número de instituiçôes na região que fornecem informações relevantes para a empresa; assim como a localização dos agentes com os quais a empresa se relaciona revelaram importante participação em nível local, notadamente para Pouso Alegre e Uberlândia.

O grau de difusão do conhecimento via mobilidade de trabalhadores especializados, como também o grau de difusão informal de informação via 
TABELA 17

Indicadores referentes à Importância do Ambiente Local: difusão do conhecimento via rotatividade de trabalhadores especializados (\% de respostas sim) e difusão de informações via conversas informais com profissionais do setor (\%)

\begin{tabular}{|c|c|c|c|c|}
\hline & Conjunto & Uberlândia & Pouso Alegre & Resende \\
\hline \multicolumn{5}{|l|}{$\begin{array}{l}\text { Difusão do conhecimento via rotatividade } \\
\text { de trabalhadores especializados }\end{array}$} \\
\hline $\begin{array}{l}\text { Considera que existe mobilidade de } \\
\text { trabalhadores especializados na região? }\end{array}$ & 38,88 & 50,00 & 33,33 & 33,33 \\
\hline $\begin{array}{l}\text { Essa mobilidade contribui para } \\
\text { aumentar } \\
\text { os conhecimentos das firmas? }\end{array}$ & 22,22 & 33,33 & 16,66 & 16,66 \\
\hline $\begin{array}{l}\text { A empresa incorporou trabalhadores de } \\
\text { outras firmas nos últimos cinco anos? }\end{array}$ & 44,44 & 16,66 & 66,66 & 50,00 \\
\hline \multicolumn{5}{|l|}{$\begin{array}{l}\text { Difusão de informações via conversas } \\
\text { informais com profissionais do setor }\end{array}$} \\
\hline Freqüência semanal ou diária & 44,44 & 33,33 & 66,66 & 33,33 \\
\hline $\begin{array}{l}\text { Número de profissionais participantes } \\
\text { (média por empresa) }\end{array}$ & 05,50 & 05,00 & 06,83 & 04,66 \\
\hline Grupo estável de profissionais & 55,55 & 50,00 & 66,66 & 50,00 \\
\hline $\begin{array}{l}\text { Participação local no grupo de } \\
\text { profissionais }\end{array}$ & 71,42 & 75,00 & 78,56 & 76,60 \\
\hline $\begin{array}{l}\text { Predominância de assuntos voltados } \\
\text { para cooperação e inovação }\end{array}$ & 43,09 & 41,86 & 43,85 & 43,58 \\
\hline
\end{tabular}

Fonte: pesquisa de campo realizada pelo autor.

conversas informais mostraram-se importantes mecanismos de difusão nas três cidades, indicadores importantes para a caracterização da importância do ambiente local.

Dessa maneira, revela-se um alto grau de importância do território local, em média, para o conjunto das empresas pesquisadas. Entre as cidades, Pouso Alegre apresenta maior regularidade, estando sempre em primeiro ou segundo lugar nos diversos indicadores examinados, e demonstrando melhores resultados em relação à participação do ambiente local nas interações e na difusão informal de informações. 
Assim, considerando os indicadores ligados às chamadas variáveis-síntese, percebe-se significativa variação entre os resultados, se considerados por cidades. Verifica-se uma tendência de cada cidade apresentar um desempenho predominantemente mais alto nos indicadores referentes a uma dessas três variáveis: Pouso Alegre, e, em menor grau, Resende, naqueles que compóem a variável Grau de alcance das atividades de desenvolvimento; Uberlândia, nos indicadores referentes à variável Índice de cooperação tecnológica; e Pouso Alegre, nos indicadores que se referem à variável Importância do ambiente local.

Em conjunto, os resultados mostram que, além das características comuns demonstradas pelo conjunto das empresas, algumas características específicas para cada cidade são reveladas. Certamente, essa constatação indica uma influência das distintas características de cada cidade (quanto ao seu processo de urbanização e à sua estrutura produtiva, em especial) sobre a capacitação tecnológica das empresas. Nessa perspectiva, conforme esperado, as características distintas quanto ao processo de urbanização e à estrutura produtiva, tenderiam a influenciar diferentemente a capacitação tecnológica de cada cidade.

\subsection{Fontes de conhecimento e terceirização no processo produtivo}

Quando perguntado onde a empresa adquiriu os conhecimentos para realizar os desenvolvimentos apontados, as respostas obtidas são as que constam da Tabela 18.

De acordo com os resultados, essas fontes podem ser classificadas em cinco grupos, por ordem de importância. O primeiro grupo reúne as três fontes que alcançaram a maior participação. Em primeiro lugar, foram citados os "clientes". Em seguida, foram indicados como fontes os "internos da empresa" e as "revistas especializadas". Um segundo grupo, ainda entre as fontes muito importantes, pode ser composto por duas fontes externas à empresa: "fornecedores" e "feiras".

Outras seis fontes podem ser reunidas num terceiro grupo, correspondendo às fontes de média importância: "viagens ao exterior"; "universidades"; "rodadas de negócios”; "instituições privadas"; "instituiçôes/governo municipal" e "consultores privados", citadas em ordem decrescente. Um quarto grupo, que pode ser caracterizado como de fontes de pequena importância, é formado pela "cooperação internacional" e pelos "acordos de cooperação". 
TABELA 18

Fontes de conhecimentos para as empresas por cidade

\begin{tabular}{|c|c|c|c|c|}
\hline Fonte & Conjunto & Uberlândia & Pouso Alegre & Resende \\
\hline Clientes & 66,66 & 66,66 & 83,33 & 50,00 \\
\hline Revistas especializadas & 61,11 & 66,66 & 83,33 & 33,33 \\
\hline Internos da empresa & 61,11 & 66,66 & 50,00 & 66,66 \\
\hline Fornecedores & 44,44 & 50,00 & 66,66 & 33,33 \\
\hline Feiras & 44,44 & 50,00 & 50,00 & 33,33 \\
\hline Viagens ao exterior & 38,88 & 16,66 & 100,00 & - \\
\hline Universidades & 27,77 & 50,00 & 33,33 & - \\
\hline Rodadas de negócios & 22,22 & 16,66 & 50,00 & - \\
\hline Consultores privados & 22,22 & 33,33 & 16,66 & 16,66 \\
\hline Instituições/Governo local & 16,66 & 33,33 & 16,66 & - \\
\hline Instituições privadas & 16,66 & - & 33,33 & 16,66 \\
\hline Acordos de cooperação & 05,55 & - & 16,66 & - \\
\hline Cooperação internacional & 05,55 & - & 16,66 & - \\
\hline Instituições/Governo Federal & - & - & - & - \\
\hline Instituições/Governo Estadual & - & - & - & - \\
\hline Câmaras & - & - & - & - \\
\hline
\end{tabular}

Fonte: pesquisa de campo realizada pelo autor.

O quinto e último grupo reúne as três fontes que não foram citadas pelas empresas: "câmaras"; "instituiçóes/governo federal" e "instituiçōes/governo estadual".

Entre as cidades, há algumas especificidades. A fonte mais citada variou entre as cidades: "clientes"; "revistas especializadas"; e "internos da empresa"; para Uberlândia, "internos da empresa" para Resende e "viagens ao exterior" para Pouso Alegre. Em Uberlândia, a fonte "universidade" alcançou seu percentual mais alto, ficando no segundo grupo de importância. 
Situadas nos dois grupos de fontes de conhecimento mais importantes para essas empresas, três fontes aparecem sempre entre as três primeiras posiçōes nas três cidades: "clientes"; "fornecedores" e "revistas especializadas". Esses resultados mostram a importância das publicações e das relações externas estabelecidas pela empresa para sua capacitação tecnológica, evidenciando o papel fundamental dos fluxos produtivos fornecedores e clientes como fonte de conhecimento da empresa. ${ }^{11}$

A pesquisa também envolveu questôes acerca das práticas de terceirização implementadas pelas empresas, com atenção para a terceirização que envolve o processo produtivo, de maneira permanente e regular.

Os resultados (Tabela 19) mostram que 15 das 18 empresas (ou cerca de $83 \%)$ revelaram alguma prática de terceirização, sendo que em 11 empresas (cerca de 61\%), a terceirização envolve parte do processo produtivo. No entanto, a parte do processo produtivo efetuada por terceiros é, em termos de valor, pequena: em média, essa parte corresponde a cerca de $3 \%$ do processo produtivo. Das três cidades, Resende foi a que apresentou maior média de terceirização do processo produtivo (estimada em cerca de 5\%), embora essa média não tenha variado muito entre as cidades. As três empresas que declararam não terceirizar qualquer atividade estão localizadas em Pouso Alegre.

\section{Considerações finais}

Os resultados verificados mostram muitos aspectos importantes relacionados ao processo de inovação. Evidentemente, em sua análise, devem-se considerar os limites da pesquisa realizada, que se refere a um grupo de empresas selecionadas sob determinados critérios. Assim, as tendências verificadas no estudo necessitam de novos levantamentos e estudos para sua comprovação e extensão para a totalidade de empresas dessas cidades.

Em relação ao conjunto de empresas situadas em cidades importantes da rede urbana brasileira, sobretudo no contexto da reconfiguração territorial na Região Sudeste, os resultados apresentados podem ser sintetizados nos seguintes pontos. Em primeiro lugar, evidencia-se que, para esse grupo de empresas,

\footnotetext{
11 Esses resultados revelam algumas semelhanças com a pesquisa de Costa \& Cunha (2001), em que os autores avaliam as principais fontes de conhecimento em um grupo de empresas na Região Metropolitana de Curitiba (PR).
} 
TABELA 19

Práticas de terceirização por empresa: percentual aproximado do processo produtivo que foi terceirizado (em termos de custo); variação no período 1995/2000; e atividades terceirizadas

\begin{tabular}{|c|c|c|c|c|}
\hline & $\begin{array}{l}\text { Terceiriza } \\
\text { atividades? }\end{array}$ & $\begin{array}{l}\text { Percentual do processo } \\
\text { produtivo(\%) }\end{array}$ & $\begin{array}{l}\text { Variação } \\
1995 / 2000\end{array}$ & Atividade(s) terceirizada(s) \\
\hline \multicolumn{5}{|c|}{ Uberlândia } \\
\hline 1 & Sim & - & Aumentou & Transporte \\
\hline 2 & Sim & 01 & Não variou & Serralheria/isolamento da tubulação \\
\hline 3 & Sim & 10 & Aumentou & $\begin{array}{l}\text { Transporte/Distribuição(parte)/envase } \\
\text { do leite longa vida }\end{array}$ \\
\hline 4 & Sim & 02 & Não variou & Acompanhamento do rebanho (zootécnica) \\
\hline 5 & Sim & 02 & Diminuiu & $\begin{array}{l}\text { Fabricação de itens da antena } \\
\text { (suporte e tubo central) }\end{array}$ \\
\hline 6 & Sim & 02 & Não variou & Montagem de acessórios \\
\hline \multicolumn{5}{|c|}{ Resende } \\
\hline 7 & Sim & 05 & Aumentou & Aluguel de máquina/plataforma e andaime \\
\hline 8 & Sim & 10 & Não variou & Curva/anodização de alumínio preto \\
\hline 9 & Sim & 10 & Aumentou & Venda e entrega/envase do leite Longa Vida \\
\hline 10 & Sim & - & Aumentou & Transporte \\
\hline 11 & Sim & 6 & Aumentou & Tratamento térmico/revestimento borracha \\
\hline 12 & Sim & - & Não variou & Recursos humanos e contabilidade \\
\hline
\end{tabular}

Pouso Alegre

\begin{tabular}{|c|c|c|c|c|}
\hline 13 & Sim & - & Não variou & $\begin{array}{l}\text { Movimentação de carga, restaurante, } \\
\text { limpeza, segurança }\end{array}$ \\
\hline 14 & Sim & 15 & Aumentou & $\begin{array}{l}\text { Usinagem, montagem elétrica, } \\
\text { serviços de solda (parte) }\end{array}$ \\
\hline 16 & Não & - & Não variou & - \\
\hline 17 & Sim & 02 & Aumentou & $\begin{array}{l}\text { Pintura, colagem, montagem/portaria, } \\
\text { restaurante, limpeza, parte elétrica }\end{array}$ \\
\hline
\end{tabular}

Fonte: pesquisa de campo realizada pelo autor. 
são privilegiadas as atividades inovativas ligadas diretamente à produção (como Controle de qualidade e Envolvimento dos operários nessas tarefas). Já as atividades mais específicas do processo de inovação, ligadas a indicadores como Capacitação de pessoal (voltada para a inovação) e Peso dos novos produtos no faturamento, que mostram a importância conferida à inovação na empresa, alcançam um patamar menor de importância. Esses resultados também se verificam em relação às fontes de conhecimento utilizadas pela empresa, pois ficou caracterizada uma grande importância dos fluxos produtivos (fornecedores e clientes) como fontes de conhecimento, resultado que ressalta também o papel proeminente das fontes externas.

O segundo ponto indicado pelos resultados consiste em que as empresas pesquisadas demonstraram uma participação importante das interações externas para sua capacitação tecnológica. Essa importância ficou demonstrada tanto nos indicadores ligados à capacidade inovativa, quanto em relação às fontes de conhecimento para as empresas. $\mathrm{O}$ terceiro ponto refere-se à participação do território local nos processos ligados à capacitação tecnológica, que atingiu um patamar alto para o conjunto das empresas, tanto em relação à capacidade inovativa, quanto em relação às fontes de conhecimento.

Os resultados mostram ainda que uma grande parte das empresas implementa práticas de terceirização, sendo que, na maior parte dos casos, essas práticas envolvem atividades do processo produtivo. Entretanto, em termos de valor, a parcela do processo produtivo que é terceirizada é, geralmente, muito pequena.

Além dessas tendências verificadas para o conjunto de empresas, podem-se analisar os resultados por cidade, trazendo novos elementos para o debate. Percebe-se que, mesmo tratando-se de grupos semelhantes de empresas em cada cidade, em termos de setores e tamanhos, existem variaçóes significativas nos resultados entre cidades, sobretudo nas variáveis-síntese. Embora com os limites explicitados quanto à metodologia, pode-se buscar relacionar essas variações por cidade com as características referentes à urbanização e à estrutura produtiva de cada cidade.

Dentre as cidades, Uberlândia alcançou o melhor desempenho nos indicadores referentes ao Índice de cooperação tecnológica, demonstrando maior tendência para o estabelecimento de vínculos externos pelas empresas. Cer- 
tamente, esse resultado está, em parte, ligado à existência de um maior número de empresas nessa cidade, comparativamente às outras duas. Além disso, pode haver uma tentativa de compensar a maior distância em relação à RMSP por meio da cooperação e dos vínculos externos. Pouso Alegre alcançou o melhor desempenho em vários indicadores relacionados à Importância do ambiente local, relacionada à proporção do território local nas interaçôes efetuadas pela empresa, como número de agentes (empresas e instituiçóes) que disponibiliza informações relevantes e grau de difusão informal de informação. Certamente, as características da cidade e da região, com muitos centros de pequeno e médio porte, próximos entre si, contribuem para esse resultado. Resende atingiu o melhor desempenho em relação ao Grau de exclusividade do pessoal envolvido em atividades inovativas, um indicador de maior consciência da importância da atividade inovativa.

Assim, as variações significativas nos resultados entre as cidades podem ser consideradas indícios de que características próprias de cada território local, como o processo de urbanização e a estrutura produtiva, desempenham um importante papel na explicação de especificidades da capacitação tecnológica das empresas. Dessa maneira, assim como esperado, verifica-se a grande importância do território local para a capacidade inovativa e tecnológica das empresas. Os resultados sugerem, além disso, que as especificidades e o perfil da capacitação tecnológica em cada cidade são influenciados, em grande medida, pela estrutura produtiva da cidade e pelo padrão de urbanização da região em que a cidade se situa.

Em síntese, o desenvolvimento de novas abordagens e concepções acerca da inovação tecnológica tem consolidado a visão de que a inovação é um processo interativo e localizado. Nesse contexto, os estudos referentes à inovação têm buscado, crescentemente, incorporar a importância do ambiente em que a empresa está inserida. O estudo desenvolvido neste trabalho mostrou resultados que se encaixam nessa perspectiva.

Os resultados verificados nas empresas pesquisadas mostram que: $i$ ) as atividades inovativas diretamente ligadas à produção têm sido priorizadas em relação àquelas especificamente voltadas para a inovação; ii) é grande a importância do território local para a capacitação tecnológica da empresa, tanto em relação à capacidade inovativa, quanto em relação às fontes de conhecimento; 
iii) a maior parte das empresas realiza práticas de terceirização da sua produção. Em geral, a parte terceirizada do processo produtivo é pequena, em termos de valor, mas mostra tendência de crescimento no período pesquisado; e iv) ocorre significativa variação dos resultados entre as cidades, mesmo tratando-se de empresas de setores e tamanhos semelhantes, o que aponta para a importância das características do território local na explicação de especificidades ligadas à capacitação tecnológica da empresa.

Assim, as empresas pesquisadas apresentam características relacionadas à capacitação tecnológica que são enfatizados pelas recentes abordagens e concepções acerca do processo de inovação. Em especial, destaca-se a grande importância das interações e do território local para a capacidade inovativa e para as fontes de conhecimento da empresa. 


\section{Referências bibliográficas}

Andrade, T.; Serra, R., "Distribuição Espacial da Indústria: Possibilidades Atuais para sua Investigação", Estudos Econômicos, v.30, n.2, p.207-231, abr./jun., 2000.

Barroso, I.C., "Los Nuevos Espacios Ganadores y Emergentes", Revista EURE, v.24, n.73, p.5-30, 1998.

Boscherini, F.; López, M.; Yoguel, G., "Sistemas Locales de Innovación y Desarollo de la Capacidad Innovativa de las Firmas: Un Instrumento de captación aplicado al caso de Rafaela", in Cassiolato, J.; Lastres, H. (orgs.) Globalização e Inovação Localizada: experiências de sistemas locais no Mercosul, Brasília: IBICT; MCT, p.569-605, 1999.

Britto, J., Redes de Firmas: Características Estruturais e modus operandi de redes de firmas em condiçôes de diversidade tecnológica setorial, Rio de Janeiro: IE/UFRJ, tese de doutorado, 1999.

, "Cooperação Interindustrial e redes de empresas", in Kupfer, D.; Hasenclever, L., Economia Industrial: Fundamentos Teóricos e Práticas no Brasil, Rio de Janeiro: Editora Campus, 2002.

Carleial, L., Sistemas Regionais de Inovação (SRI) e Relação entre Firmas: as "pistas" para um formato de desenvolvimento Regional. In VII Encontro Nacional da ANPUR. Recife, v.2, p.811-834, 1997.

Camagni, R., "Espace et temps dans le concept de milieu innovateur", in Rallet, A.; Torre, A. (coords.), Économie Industrielle et Économie Spatiale, Paris: Ed. Economica, p.193-210, 1995.

Costa, V.; Cunha, J.C., "A Universidade e a Capacitação Tecnológica das Empresas", Revista da Administração Contemporânea, v.5, n.1, jan./abr., p.61-81, 2001.

Debresson, C.; Amesse, F., "Networks of innovators: A review and introduction to the issue", Research Policy, 20, p.363-379, 1991.

, An entrepreneur cannot innovate alone: networks of enterprises are required., 1999. Disponível em <http://www.business.auc.dk>.

Diniz, C.C., "Desenvolvimento poligonal no Brasil: nem desconcentração, nem contínua polarização", Nova Economia, Belo Horizonte, v.3, n.1, set., p.3564, 1993. 
Dosi, G.; Orsenigo, L., "Coordination and transformation: na overview of structures, behaviours and change in evolutionary environments", in Dosi, G.; Freeman, C.; Nelson, R.R.; Soete, L., Technical Change and Economic Theory, Londres: Pinter, p.3-37, 1988.

Druck, M.G., Terceirização: (des)fordizando a fábrica - Um estudo do complexo petroquimico, Bahia: EDUFBA, 1.ed., 1999.

Freeman, C., "Japan, a Newbb System of Innovation”, in Dosi, G. et al., op. cit., Londres: Pinter, p.330-348, 1988.

Hasenclever, L.; Cassiolato, J., "Capacitação Tecnológica Empresarial Brasileira e Transferência de Tecnologia”, SIMPÓSIO DE GESTÃO DA INOVAÇÃO TECNOLÓGICA, 20, São Paulo, 1988. Anais..., p.309-321, 1988.

Lastres, H.; Cassiolato, J.; Lemos, C.; Maldonado, J.; Vargas, M.A., "Globalização e inovação localizada", in Cassiolato, J.; Lastres, H. (orgs.). Globalização e Inovação Localizada: experiências de sistemas locais no Mercosul, Brasília: IBICT, MCT, p.39-71, 1999.

Lastres, H.; Cassiolato, J.; Maciel, M. (orgs.), Pequena empresa: cooperação e desenvolvimento Local, Rio de Janeiro: Ed. Relume Damará, 2003.

Lecoq, B., "Des formes locales d'organisation productive aux dynamiques industrielles localisées: bilan et perspectives", in Rallet, A.; Torre, A. (coords.), Économie Industrielle et Économie Spatiale, Paris: Ed. Economica, p.233-252, 1995.

Lundvall, B.-A., "Innovation as an interactive process: from user-producer interaction to the national system of innovation", in Dosi, G. et al., op. cit, Londres: Pinter, 1988, p.349-369, 1988.

Pacheco, C., "Desconcentração econômica e fragmentação da economia nacional", Economia e Sociedade, v.6, p.113-140, jun., Campinas (SP): 1996.

Silva, C., "Inovação e Cooperação: O Estado das Artes no Brasil", Revista do BNDES, v.7, n.13, p.65-88, 2000.

Yoguel, G.; Boscherini, F., La capacidad innovativa y el fortalecimiento de la competritividad de las firmas: el caso de las Pymes exportadoras argentinas, CEPAL, Documento de Trabajo n.71, Buenos Aires, 1996. 